\title{
The Effect of Thyroid-stimulating Hormone on Tumor Size in Differentiated Thyroid Carcinoma
}

\author{
İbrahim Atak ${ }^{1}$, Mehmet Lütfi Polat ${ }^{1}$, Tuba Atak ${ }^{2}$, (1) Serkan Fatih Yeğen 1, (i) Erol Bağcivan ${ }^{1}$, \\ Alaattin Güler ${ }^{1}$, (1) Mehmet Veysi Samsa1 \\ ${ }^{1}$ Department of General Surgery, Ali Osman Sonmez Oncology Hospital, Bursa, Turkey \\ ${ }^{2}$ Department of General Surgery, Cekirge State Hospital, Bursa, Turkey
}

\begin{abstract}
Introduction: The effect of thyroid-stimulating hormone (TSH) on the development and progression of thyroid cancer is not clear. This study was performed to investigate the effect of TSH on the tumor size and invasiveness in well-differentiated thyroid cancer.

Methods: A total of 331 patients undergoing thyroidectomy in the general surgery department of our hospital between 2015 and 2017 were evaluated. Laboratory findings, demographic characteristics, and the pathology reports of patients were retrospectively evaluated. Patients with normal pre-operative serum TSH levels $(0.4-4.0 \mathrm{mU} / \mathrm{L})$ and below the lower limit of the normal range (0.4 mU/L) were classified as "normal TSH group" (NTG) and "Iow TSH group" (LTG), respectively. Tumor multicentricity, tumor capsular invasion, thyroid carcinoma with capsular invasion, and lymphovascular invasion were investigated. Chi-square test, Student's t-test, and Mann-Whitney U-tests were used for statistical analysis.

Results: Differentiated thyroid cancer was determined in a total of 73 patients including 63 in NTG and 10 in LTG. Mean tumor diameter was determined to be $15.52 \pm 14.01 \mathrm{~mm}$ and $14.00 \pm 15.47 \mathrm{~mm}$ in NTG and in LTG, respectively. There was no statistically significant difference between the two groups with respect to tumor size $(p=0.450)$. Although NTG had a higher rate of tumor multicentricity, tumor capsular invasion, thyroid carcinoma with capsular invasion, and lymphovascular invasion, there was no statistically significant difference between the two groups.

Discussion and Conclusion: In our study, no relationship was determined between pre-operative serum TSH levels and tumor size and invasiveness. Prospective, randomized controlled studies are needed on this subject.

Keywords: Microcarcinoma; thyroid cancer; thyroid-stimulating hormone; tumor size.
\end{abstract}

T he most frequently seen type of cancer in the endocrine system is thyroid cancer. The incidence of the disease increases more rapidly than other types of cancer. Since 1975 , its frequency has increased $3-$ fold $_{1}{ }^{[1]}$ with survival rate of $97 \%$ in - well-differentiated thyroid cancers ${ }^{[2]}$. Thyroid-stimulating hormone (TSH) is a well-known thyrocyte growth factor ${ }^{[3]}$. The hormone synthesized in the gland has a glycoprotein structure and consists of alpha and beta su- bunits. TSH is the most important regulator of the development and function of the thyroid gland ${ }^{[4,5]}$. Some studies have revealed that TSH increases the incidence of thyroid cancer in patients with nodular thyroid disease. The effect of TSH on the development and progression of thyroid cancer is still unclear ${ }^{[6]}$. In this study, it was aimed to investigate the effect of pre-operative serum TSH level on tumor size and tumor invasion in patients with thyroid cancer.

Correspondence (İletişim): İbrahim Atak, M.D. Ali Osman Sönmez Onkoloji Hastanesi, Genel Cerrahi Kliniği, Bursa, Turkey Phone (Telefon): +90 5056005412 E-mail (E-posta): driatak@yahoo.com 


\section{Materials and Methods}

A total of 331 patients who underwent thyroidectomy with the indications of nodular goiter, multinodular goiter, toxic goiter, thyroid carcinoma, or suspect carcinoma were evaluated in general surgery clinic our hospital between April 2015 and March 2017. Pre-operative serum-free T3, free T4 and TSH values, demographic characteristics, and pathology reports of the patients were retrospectively analyzed.

Patients with normal serum TSH levels (0.4-4.0 mU/L) were classified as "normal TSH group" (NTG) and patients with TSH score $<0.4 \mathrm{mU} / \mathrm{L}$ were classified as "low TSH group" (LTG). Tumor size was determined according to the largest diameter detected in the pathology report. The two groups were compared in terms of tumor size, tumor multicentricity, tumor capsule invasion, thyroid capsule invasion, and lymphovascular invasion. Microcarcinoma was considered to be $1 \mathrm{~cm}$ smaller than the largest diameter of the tumor. Chi-square test, Student's t-test, and Mann-Whitney U-test were used for statistical analysis.

\section{Results}

Within 2 years, 331 patients (mean age, 50.52 12.08 years) underwent thyroidectomy. Unilateral total thyroidectomy was performed in $34(10.3 \%)$, total thyroidectomy in 2 (0.6\%), and bilateral total thyroidectomy in 295 ([female, $n=292: 88.2 \%$ and male, $n=39: 11.8 \%]$ ) patients (89.1\%).

Differential thyroid carcinoma (DTC) was detected in 73 patients, including 63 patients in the NG and 10 patients in the dental treatment group (DTG). Of these patients, 60 (82.1\%) were female and $13(17.9 \%)$ were male. The mean age was $46.1 \pm 13$ years in the DTG and $46.7 \pm 17$ years in the NTG group. There was no difference in demographic characteristics between the two groups ( $p>0.05$ ).

The mean tumor diameter was $15.52 \pm 14.01 \mathrm{~mm}$ in the NTG and $14.00 \pm 15.47 \mathrm{~mm}$ in the LTG groups. There was no statistically significant difference in tumor size between the two groups ( $r=0.066, P=0.450$, Fig. 1). Histopathological examination revealed papillary microcarcinoma (PMC) in $29(39.72 \%)$ patients of these, $24(38.1 \%)$ patients were in the NTG and $5(50 \%)$ in the DTG group. There was no statistically significant difference in the incidence of microcarcinomas between the two groups $(p=0.505)$.

Despite the higher incidence of multicentricity, tumor capsule invasion, thyroid capsule invasion, and lymphovascular invasion in NTG, there was no statistically significant difference between the two groups (Table 1).

\section{Discussion}

Thyroid cancer accounts for $90 \%$ of all endocrine system cancers, $1 \%$ of all cancers, and $0.2 \%$ of cancer-related deat-

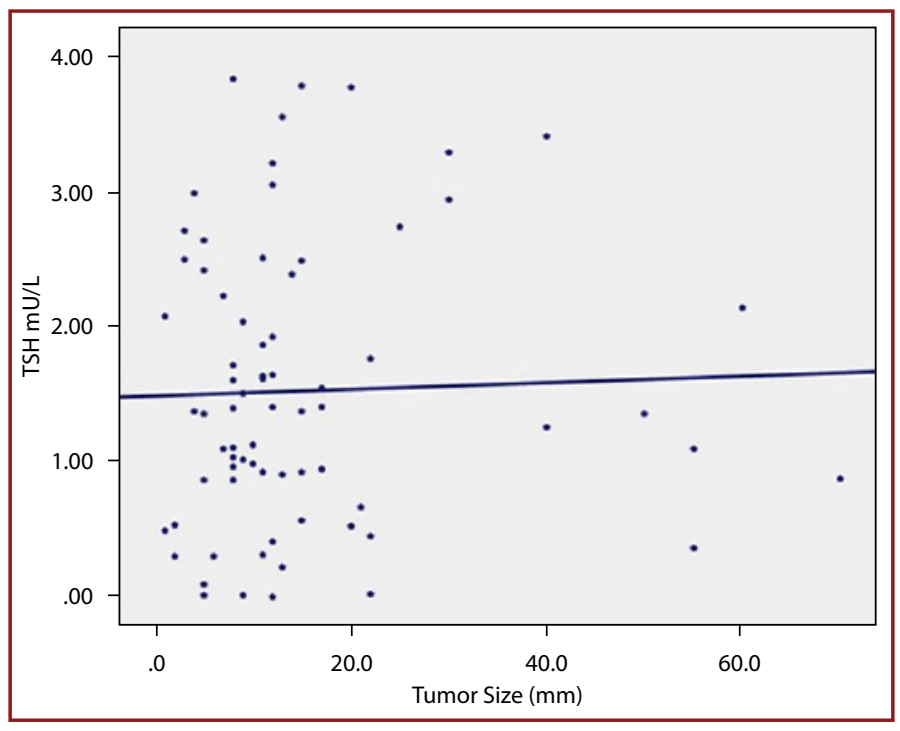

Figure 1. Graphics demonstrating correlation between thyroid-stimulating hormone and tumor size.

Table 1. Comparisons of TSH levels

\begin{tabular}{|c|c|c|c|}
\hline & TSH level & Test value & \\
\hline & Normal $n=63(\%)$ & Low $n=10(\%)$ & \\
\hline \multicolumn{4}{|l|}{ Tumor size (mm) } \\
\hline Minimum-Maximum (Median) & $1-70(12)$ & $2-55(10)$ & Z:-0.756 \\
\hline \multirow[t]{2}{*}{ Mean $\pm S D$} & $15.52 \pm 14.01$ & $14.00 \pm 15.47$ & ${ }^{a} 0.450$ \\
\hline & n (\%) & n (\%) & \\
\hline Multicentricity & $9(14.2)$ & $2(20.0)$ & $\mathrm{b}_{0} 0.648$ \\
\hline PMC & $24(38.1)$ & $5(50.0)$ & $\mathrm{b}_{0.505}$ \\
\hline Tumor capsule invasion & $11(18.6)$ & $0(0.0)$ & $\mathrm{b}_{0.345}$ \\
\hline Thyroid capsule invasion & $13(21.3)$ & $1(10.0)$ & $\mathrm{b}_{0.674}$ \\
\hline Lymphovascular invasion & $5(8.1)$ & $0(0.0)$ & $\mathrm{b}_{1.000}$ \\
\hline
\end{tabular}

aMann-Whitney U-test; ${ }^{\text {b}}$ Fisher's exact test; PMC: Papillary microcarcinoma. 
hs worldwide ${ }^{[7]} .80-90 \%$ of thyroid cancers constitute papillary carcinoma ${ }^{[8]}$. TSH is major stimulant together with growth factors and some cytokines in the function and development of thyroid gland. In some studies, TSH has been shown to have a mitogenic effect on the thyroid gland of animals ${ }^{[9]}$. Although DTC is implicated in the involvement of TSH receptors, the same effect has not been clearly demonstrated on human thyroid gland ${ }^{[10]}$.

A number of studies have examined the relationship between thyroid cancer and high TSH levels. Boelaert et al. ${ }^{[11]}$ suggested that elevated TSH concentration may be a predictor for thyroid malignancy. In a meta-analysis ${ }^{[12]}$ of 5605 patients published in 2012, patients with a TSH level of $4 \mathrm{~m} \mathrm{IU} / \mathrm{lt}$ were more than twice as likely to have cancer at a TSH level of $0.65 \mathrm{~m} \mathrm{IU} / \mathrm{lt}$. Franco et al. ${ }^{[13]}$ have demonstrated that TSH plays a key role in the initiation of Braf-induced papillary thyroid cancer in the mouse model.

Haymart et al. have revealed that preoperatively high serum TSH concentration is not only associated with the incidence of DTC but also at the time of diagnosis it is associated with advanced cancer stage. ${ }^{[14]}$ In a similar study, Fiore et al. ${ }^{[15]}$ found that serum TSH concentrations in patients with T3-T4 tumors were higher relative to patients with T1T2 disease. In our study, although there was no statistically significant difference between the two groups, tumor capsule invasion, thyroid capsule invasion, and lymphovascular invasion were more frequent in the NTG group.

Papillary carcinoma is called microcarcinoma when its largest diameter is $>10 \mathrm{~mm}$. The incidence of PMC ranges from $9 \%$ to $47 \% .{ }^{[5,16]}$ It is now stated that the increase in the diagnosis of PMC is a result of technological progress in imaging methods. ${ }^{[17]}$ PMC usually has good prognosis and the 10 -year mortality rate is between $0 \%$ and $1 \% .{ }^{[18]}$ In our study, PMC was detected in 29 patients (39.72\%) including 24 in NTG and 5 in DTG group without any statistically significant difference between the groups.

In some studies, the prevalence of multicentric tumors in papillary thyroid carcinoma patients has been reported to be approximately $25-88 \%$. In our study, multicentric tumor was detected in 11 (15.0\%) patients of these, 2 (20\%) were in the LTG group and 9 (14.8\%) were in the NTG group. Lymphovascular invasion and capsule invasion were higher in the LTG group than in the NTG group, without any statistically significant intergroup difference.

There are also studies in literature showing lack of any correlation between TSH level and incidence of DTC and poor prognosis. ${ }^{[19,20]}$ In a large patient-centered study, Kim et al. ${ }^{[21]}$ were unable to detect a relationship between se- rum TSH levels and thyroid cancer as in our study. In a recent study, Sohn et al. ${ }^{[22]}$ found no significant association between TSH levels and thyroid PMC. However, in the same study, a significant correlation was found between serum TSH levels and thyroid papillary macrocarcinoma. The lack of significant clinical benefit of exogenous thyroid hormone and TSH suppression in patients with low-risk thyroid cancer ${ }^{[23]}$ and the lack of evidence of a direct oncogenic role of TSH in human thyroid carcinogenesis ${ }^{[10]}$ tends to support studies in this respect.

\section{Conclusion}

There is a large body of data exploring the relationship between TSH and thyroid cancer. However, there is still debate in this regard. It is still unclear whether TSH is a true pathogenic factor or contributing factor in tumor progression. In our study, no relation was found between pre-operative TSH level and tumor size and its invasiveness. Conduction of prospective randomized studies on this subject is needed.

Peer-review: Externally peer-reviewed.

Authorship Contributions: Concept: I.A., E.B.; Design: I.A., M.L.P., M.V.S.; Data Collection or Processing: A.G., T.A.; Analysis or Interpretation: S.F.Y.; Literature Search: E.B., A.G.; Writing: I.A.

Conflict of Interest: None declared.

Financial Disclosure: The authors declared that this study received no financial support.

\section{References}

1. Davies L, Welch HG. Current thyroid cancer trends in the United States. JAMA Otolaryngol Head Neck Surg 2014;140:317-22.

2. Yu XM, Schneider DF, Leverson G, Chen H, Sippel RS. Follicular variant of papillary thyroid carcinoma is a unique clinical entity: a population-based study of 10,740 cases. Thyroid 2013;23:1263-8. [CrossRef]

3. Kim D, Park JW. Clinical implications of preoperative thyrotropin serum concentrations in patients who underwent thyroidectomy for nonfunctioning nodule(s). J Korean Surg Soc 2013;85:15-9. [CrossRef]

4. Shi L, Li Y, Guan H, Li C, Shi L, Shan Z, Teng W. Usefulness of serum thyrotropin for risk prediction of differentiated thyroid cancers does not applyto microcarcinomas: results $1,870 \mathrm{Chi}-$ nese patients with thyroid nodules. Endocr J 2012;59:973-80.

5. Zafon C, Obiols G, Baena JA, Castellvi J, Dalama B, Mesa J. Preoperative thyrotropin serum concentrations gradually increase from benign thyroid nodules to papillary thyroid microcarcinomas then to papillary thyroid cancers of larger size. J Thyroid Res 2012;2012:530721 doi:10.1155/2012/530721.

6. Zhu C, Zheng T, Kilfoy BA, Han X, Ma S, Ba Y, et al. A birth cohort analysis of the incidence of papillary thyroid cancer in the United States, 1973-2004. Thyroid 2009;19:1061-6. 
7. Jemal A, Murray T, Ward E, Samuels A, Tiwari RC, Ghafoor A, et al. Cancer statistics, 2005. CA Cancer J Clin 2005;55:10-30.

8. Cooper DS, Doherty GM, Haugen BR, Kloos RT, Lee SL, Mandel SJ, et al; American Thyroid Association (ATA) guidelines task force on thyroid nodules and differentiated thyroid cancer. Revised American Thyroid Association management guidelines for patients with thyroid nodules and differentiated thyroid cancer. Thyroid 2009;19:1167-214. [CrossRef]

9. Goretzki PE, Koob R, Koller T, Simon R, Branscheid D, Clark OH, et al. The effect of thyrotropin and CAMP on DNA synthesis and cell growth of human thyrocytes in monolayer culture. Surgery1986;100:1053-61.

10. Yeager N, Klein-Szanto A, Kimura S, DiCristofano A. Pten loss in the mouse thyroid causes goiter and follicular adenomas: insightsinto thyroid function and Cowden disease pathogenesis. Cancer Res 2007;67:959-66. [CrossRef]

11. Boelaert K, Horacek J, Holder RL, Watkinson JC, Sheppard MC, Franklyn JA. Serum thyrotropin concentration as a novel predictor of malignancy in thyroid nodules investigated by fine needle aspiration. J Clin Endocrinol Metab 2006;91:4295-301.

12. McLeod DS, Watters KF, Carpenter AD, Ladenson PW, Cooper DS, Ding EL. Thyrotropin and thyroid cancer diagnosis: a systematic review and döşe response meta-analysis. J Clin Endocrinol Metab 2012;97:2682-92. [CrossRef]

13. Franco AT, Malaguarnera $R$, Refetoff $S$, Liao $X H$, Lundsmith $E$, Kimura $S$, et al. Thyrotrophin receptor signaling dependence of Braf-induced thyroid tumor initiation in mice. Proc Natl Acad Sci 2011;108:1615-20. [CrossRef]

14. Haymart MR, Repplinger DJ, Leverson GE, Elson DF, Sippel RS, Jaume JC, et al. Higher serum thyroid stimulating hormone level in thyroid nodüle patients is associated with greater risks of differentiated thyroid cancer and advanced tumor stage. J Clin Endocrinol Metab 2008;93:809-14. [CrossRef]

15. Fiore E, Rago T, Provenzale MA, Scutari M, Ugolini C, Basolo F, et al. Lower levels of TSH are associated to a lower risk of papillary thyroid cancer in patients with thyroid nodular disease: thyroid autonomy may play a protective role. Endocr Relat Cancer 2009;16:1251-60. [CrossRef]

16. Kamer E, Ünalp HR. Incidental papillary microcarcinoma of thyroid. JDE Endokrin 2011;8:116-9.

17. Davies $L$, Welch HG. Increasing incidence of thyroid cancer in the United States, 1973-2002. J Am Med Assoc 2006;295:2164-7.

18. Noguchi S, Yamashita H, Uchino S, Watanabe S. Papillary microcarcinoma. World J Surg 2008;32:747-53. [CrossRef]

19. Kim KW, Park YJ, Kim EH, Park SY, Park DJ, Ahn SH, et al. Elevated risk of papillary thyroid cancer in Korean patients with Hashimoto's thyroiditis. Head Neck 2011;33:691-5. [CrossRef]

20. Negro R, Valcavi R, Riganti F, Toulis KA, Colosimo E, Bongiovanni $M$, at al. Thyrotropin values in patients with micropapillary thyroid cancer versus benign nodular disease. Endocr Pract 2013;19:651-5. [CrossRef]

21. Kim HS, Lee SJ, Park JK, Jo CH, Shon HS, Jung ED. Association between serum thyroid stimulating hormone level and papillary thyroid microcarcinoma in Korean euthyroid patients. Endocrinol Metab 2011;26:297-302. [CrossRef]

22. Sohn SY, Kim HJ, Jang HW, Kim SW, Chung JH. Lack of association between high serum thyroid-stimulating hormone level and risk of papillary thyroid microcarcinomas. Head Neck 2014;36:43-6. [CrossRef]

23. Biondi B, Filetti S, Schlumberger M. Thyroid-hormone therapy and thyroid cancer: a reassessment. Nat Clin Pract Endocrinol Metab 2005;1:32-40. [CrossRef] 